\title{
The War of the Romantics: An Alternate Hypothesis Using nPVI for the Quantitative Anthropology of Music
}

\author{
LEIGH VANHANDEL [1] \\ Michigan State University
}

\begin{abstract}
This response offers an alternate interpretation for the data described in Joseph Daniele's 2016 article “A tool for the quantitative anthropology of music: Use of the nPVI equation to analyze rhythmic variability within long-term historical patterns in music.” I examine Daniele's argument that there is an overall rising trend in rhythmic variability in German composition from 1600-1950, and offer an alternate, historically informed explanation based on the re-examination of the data. The rising trend does not appear to be consistent throughout time, and rather than being the result of the waning influence of Italian music on German music, I suggest an alternative hypothesis concerning documented differences between late $19^{\text {th }}$ century German composers and their compositional styles.
\end{abstract}

Submitted 2016 March 29; accepted 2016 May 15.

KEYWORDS: historical trends, quantitative musicology, corpus study, rhythm, $n P V I$

\section{INTRODUCTION AND BACKGROUND}

IN his 2016 article " $A$ tool for the quantitative anthropology of music: Use of the nPVI equation to analyze rhythmic variability within long-term historical patterns in music,” Joseph Daniele continues his line of research into whether the nPVI measurement, a measurement of rhythmic variability originally applied to language, can help illuminate historical shifts in how composers use rhythm.

Daniele's starting point for this article is an earlier finding (Daniele \& Patel 2013) that German/Austrian nPVI values increased steadily from 1600 to 1950 while Italian composers did not show a similar increase. This was measured by using the mean nPVI for each composer plotted against the composer's midpoint year (the mathematical average of the composer's birth and death year). Daniele and Patel (2013) argued that this increase in German/Austrian rhythmic variability is the result of the waning influence of Italian music on German music beginning in the second half of the $18^{\text {th }}$ century.

In this article, Daniele extends this hypothesis by investigating the proportion of low, middle and high nPVI values for eleven German/Austrian composers and comparing these proportions to those of an unspecified group of Italian composers. These categories were created by using the median nPVI values for the German composers in the "Baroque/Classical" period (median nPVI = 32.2) and "Romantic" period (median nPVI $=43$ ), resulting in bins of nPVIs less than 32.2 for low, between 32.2 and 43 for middle, and greater than 43 for high. Daniele then demonstrates that German composers with later midpoint years have a higher proportion of themes with higher rhythmic variability, and a smaller proportion of themes with lower rhythmic variability, during the time period from 1700-1910 (see Figure 1, which reproduces Daniele's Figure 1). Daniele's explanation for this trend is the "Replacement Hypothesis," which is that music with low rhythmic variability is being replaced by music with high rhythmic variability through this time period, which he claims supports the "waning influence" theory. 


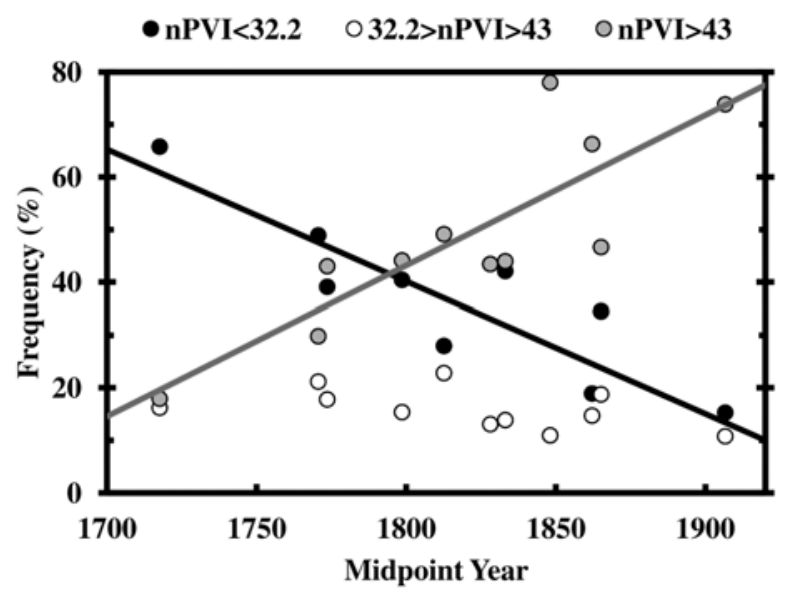

Figure 1. Figure 1 from Daniele (2016; reproduced). There is an error in the description of the "middle" bin in the legend of this chart; it should read "32.2 < nPVI < 43", to indicate that the nPVI value in that group is between 32.2 and 43 .

\section{METHODOLOGICAL CONCERNS}

There are some concerns with methodology that will not be fully addressed in this response. First, as discussed in London (2013), the Barlow and Morgenstern Dictionary for Musical Themes, which is the source for the data for both Daniele and Patel (2013) and Daniele (2016), is not necessarily a representative corpus. Of particular concern to this study is the under-representation of the German Baroque and the overrepresentation of Romantic composers of questionable historical significance.

Second, the use of the "midpoint year" to represent a composer in time is problematic. Daniele and Patel (2015) defend the use of the midpoint year, but their study again relied on the Barlow and Morgenstern Dictionary, and included only four composers (Bach, Mozart, Beethoven, and Brahms). In my own work (VanHandel, 2006 and elsewhere), using a much larger musical corpus for individual composers, I have found that compositional style does not necessarily stay constant over the lifetime of the composer, so I am skeptical that a single data point can accurately capture the rhythmic profile of a composer.

Third, the description of the creation of the low, middle, and high bins is not entirely clear, and it concerns me that the same data used to create the boundaries for the bins was then categorized into the bins to describe compositional style. There is not enough justification for why 32.2 constitutes the upper boundary of the low bin or why 43 constitutes the lower boundary of the high bin, and the resulting middle bin is comparatively quite small in size to the other two bins.

However, the remainder of this response will use the same data set, criteria, and methodology as the Daniele (2016) paper so as to make a direct comparison and illustrate an alternate interpretation of the data.

\section{CORPUS AND DATA}

There are eleven German/Austrian composers represented in this study, as listed in Daniele's Table 1. Critically, only three composers - J.S. Bach, Haydn, and Mozart - are included in Daniele's combined "Baroque/Classical" period of 1600-1810, with Bach alone constituting the Baroque (1600-1750) and Haydn and Mozart comprising for the data for the Classical (1750-1810) period. (Although Beethoven's midpoint year is 1798, Daniele classifies Beethoven as a Romantic composer.)

The eleven composers used in this study are a subset of the German/Austrian composers used in Daniele and Patel 2013. Daniele states that the selection criteria for this study were the same as those used in the earlier study, with the exception of a revision of the minimum number of themes from 15 in the 2013 study to 75 here. Because of this revision, there are eight Baroque/Classical and Romantic composers, listed in Table 1 below, who were included in the 2013 study but who are not represented here. [2] 
Table 1. German Baroque/Classical and Romantic composers represented in Daniele and Patel (2013) but not included in Daniele (2016).

\begin{tabular}{lcccc}
\hline \multicolumn{1}{c}{ Composer } & Dates & Midpoint year & \# of themes* & Mean nPVI* \\
\hline Telemann & $1681-1767$ & 1724 & 32 & 37.9 \\
C.P.E Bach & $1714-1788$ & 1751 & 18 & 42.6 \\
von Weber & $1786-1826$ & 1806 & 48 & 45.1 \\
von Suppé & $1819-1895$ & 1857 & 30 & 52.7 \\
Bruckner & $1824-1896$ & 1860 & 60 & 48.7 \\
Bruch & $1838-1920$ & 1879 & 15 & 58.0 \\
Mahler & $1860-1911$ & 1888.5 & 57 & 45.7 \\
Reger & $1873-1916$ & 1894.5 & 23 & 41.3 \\
\hline
\end{tabular}

* data from Daniele and Patel (2013)

Including data from these composers into the current study would add more data to both the Baroque/Classical time window, which only has three data points, and to the $19^{\text {th }}$ century Romantic time period, which has eight. [3]

To add the data for these composers, the nPVI for each theme was calculated using the Humdrum toolkit and the standard nPVI command, and the themes were grouped into Daniele's (2016) "bins" as described in his Results section. Table 2, modeled after Daniele’s Table 1, illustrates the results.

Table 2. Data for composers included in Daniele and Patel (2013), but not included in Daniele (2016).

\begin{tabular}{|c|c|c|c|c|c|c|}
\hline Composer & $\begin{array}{c}\begin{array}{c}\# \text { of } \\
\text { themes* }\end{array} \\
\end{array}$ & $\begin{array}{c}\text { mean } \\
\text { nPVI* }\end{array}$ & $\begin{array}{c}\text { midpoint } \\
\text { year }\end{array}$ & $\begin{array}{c}\text { \% themes } w / \\
\text { nPVI }<32.2 \\
(\text { (low") }\end{array}$ & $\begin{array}{c}\% \text { themes w/ } \\
32.2<\text { nPVI }<43 \\
\text { ("middle") }^{\mathrm{s}} \\
\end{array}$ & $\begin{array}{l}\text { \% themes w/ } \\
\text { nPVI }>43 \\
\text { ("high") }^{\S} \\
\end{array}$ \\
\hline Telemann & 32 & 37.9 & 1724 & 38.9 & 19.4 & 41.7 \\
\hline C.P.E. Bach & 18 & 42.6 & 1751 & 26.9 & 23.1 & 50 \\
\hline von Weber & 48 & 45.1 & 1806 & 31.3 & 16.4 & 52.2 \\
\hline von Suppé & 30 & 52.7 & 1857 & 23.5 & 14.7 & 61.8 \\
\hline Bruckner & 60 & 48.7 & 1860 & 20.9 & 19.4 & 59.7 \\
\hline Bruch & 15 & 58.0 & 1879 & 16.7 & 11.1 & 72.2 \\
\hline Mahler & 57 & 45.7 & 1888.5 & 22.8 & 26.3 & 50.8 \\
\hline Reger & 23 & 41.3 & 1894.5 & 47.8 & 8.7 & 43.5 \\
\hline
\end{tabular}

* data from Patel and Daniele (2013)

$\S$ nPVI for each theme calculated using the standard nPVI command in Humdrum

Figure 3 combines the data from Table 2 with that from Daniele's (2016) Table 1 and plots the percentages against each composer's midpoint year, as in Daniele's (2016) Figure 1. 


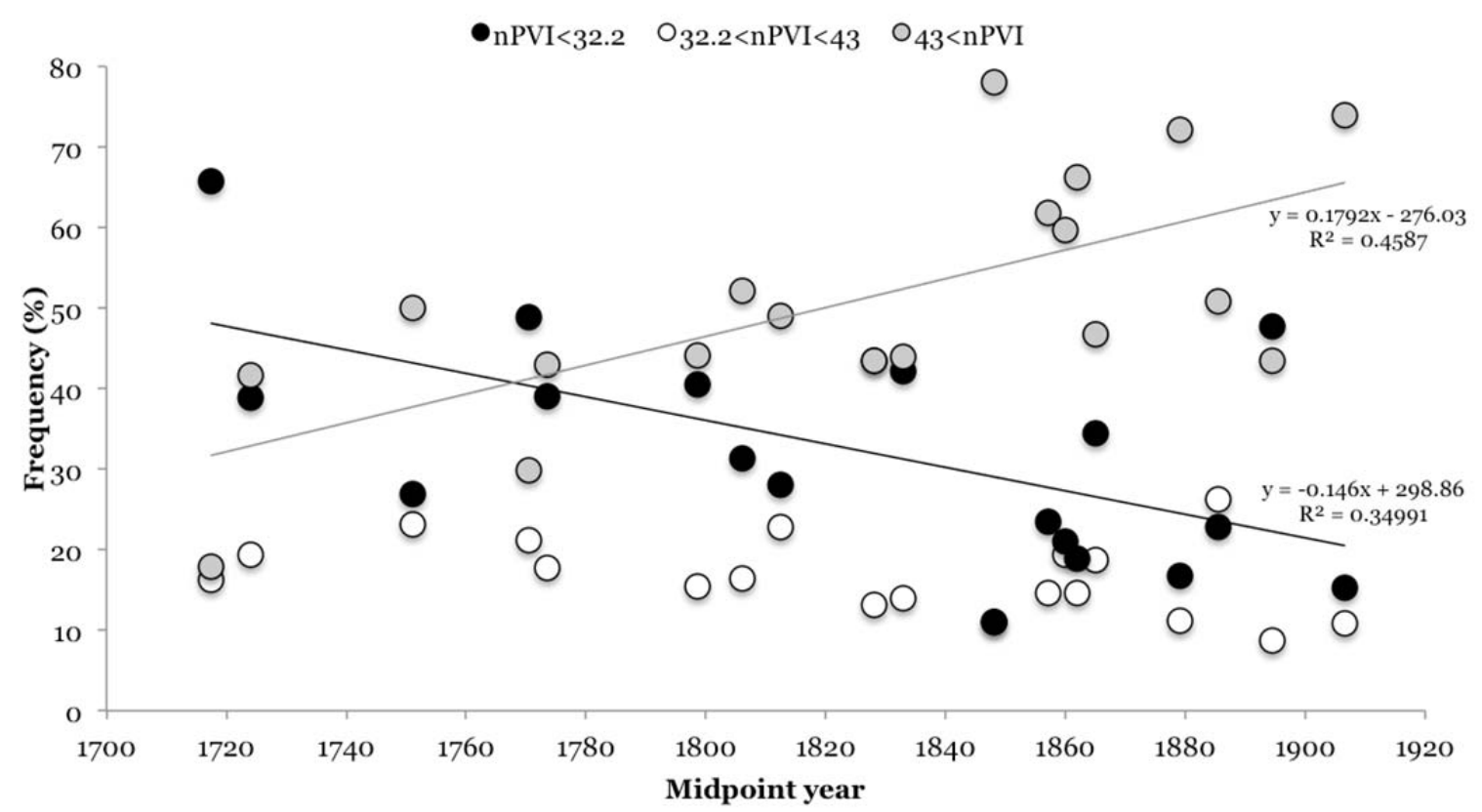

Figure 3. Data for the eight composers in Table 2 combined with the eleven from Daniele's (2016) Table 1, resulting in five Baroque/Classical data points and fourteen Romantic-era data points.

Including data for these eight composers fills in some of the gaps present in Daniele 2016's data set, but a linear regression reveals that the addition of this data reduces the $R^{2}$ value of both the high trend line (original $R^{2}=.71$, new $R^{2}=.45$ ) and the low trend line (original $R^{2}=.68$, new $R^{2}=.34$ ). Both trends remain significant, however.

\section{EXPLORING OTHER OPTIONS}

Since Daniele (2016) claims that the increase in the percentage of "high" nPVI themes is indicative of the waning influence of Italian music, it is instructive to isolate the data for that category. Figure 4 shows just the data for the percentage of "high" nPVI themes for each composer.

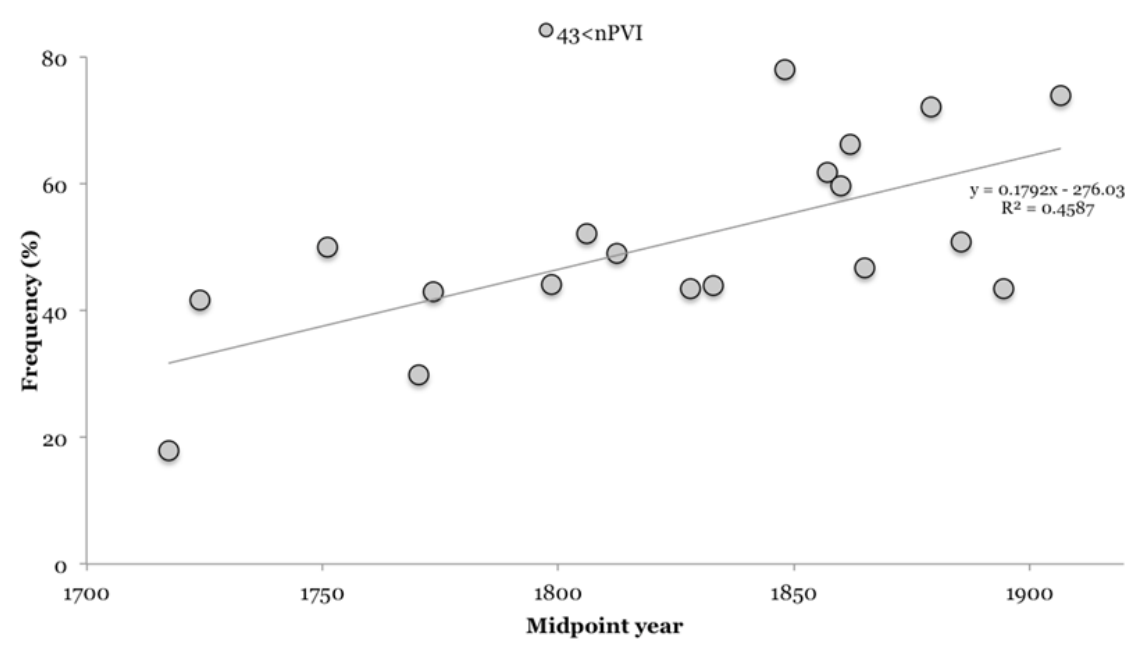

Figure 4. Composer midpoint year plotted against “high” nPVI percentage. 
Specifically, Daniele and Patel (2013) and Daniele (2016) point to the late 1700s as the primary period of transition away from the Italian influence and towards the higher variability "German" style. However, the data do not support that theory. Figure 5 shows the "high" nPVI percentage plotted against midpoint year for the composers classified as "Baroque/Classical."

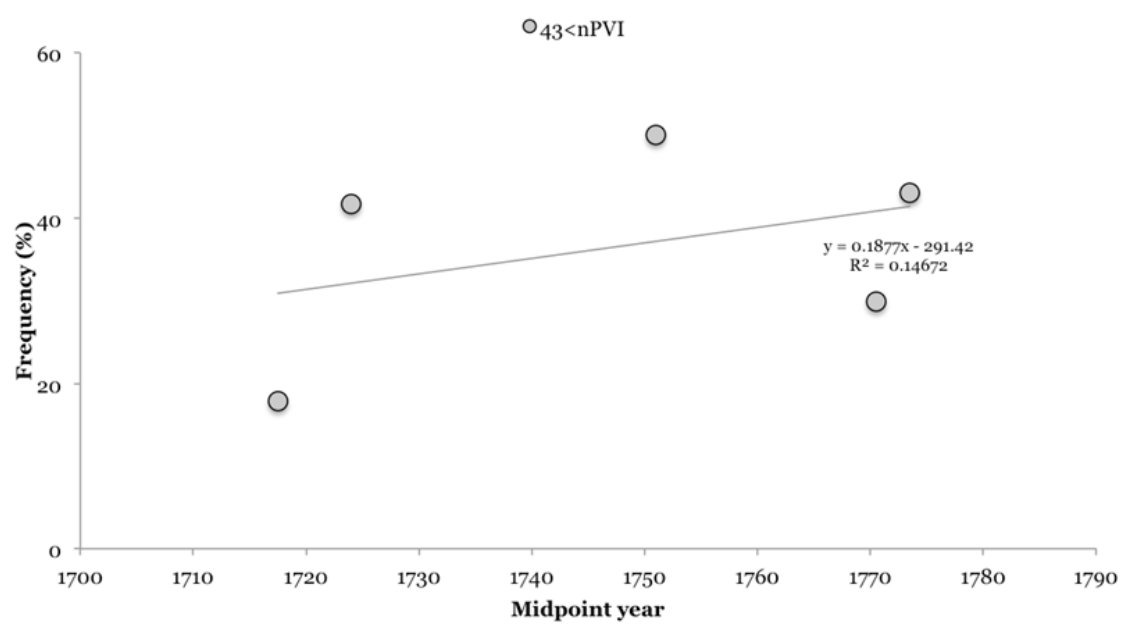

Figure 5. "High” nPVI percentage plotted against midpoint year for "Baroque/Classical” composers.

While there is a slight overall rising trend in this time period, it is not significant $\left(R^{2}=.15, p=.52\right)$ and what trend does exist is likely primarily the result of the data point for J.S. Bach (17.9\%, midpoint year of 1717.5).

Figure 6 shows the "high" nPVI percentage for composers classified as Romantic composers in this study (from Beethoven's 1798 midpoint year through Richard Strauss).

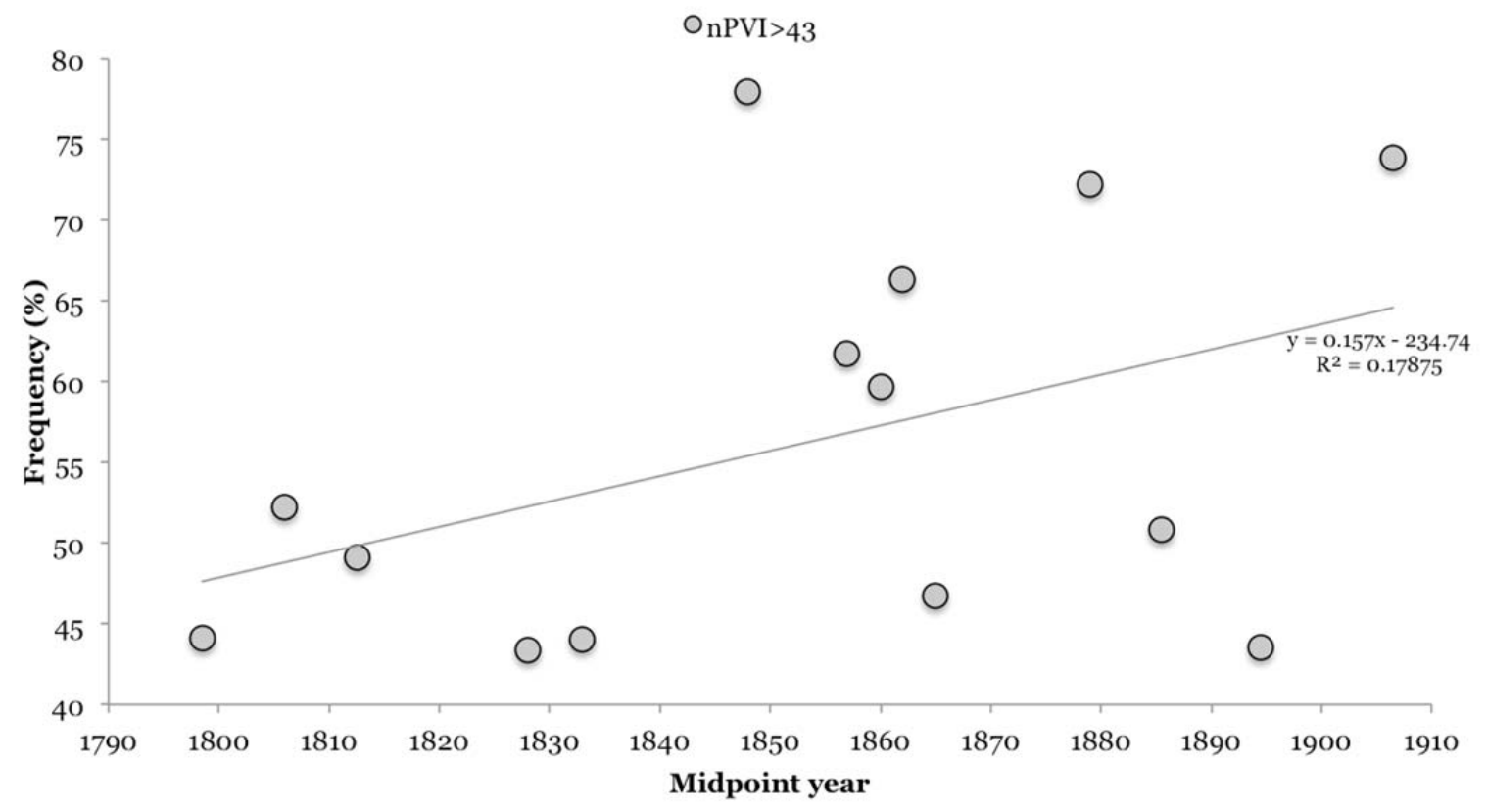

Figure 6. "High” nPVI percentage for "Romantic” composers (Beethoven through R. Strauss). 
A regression on the "high" $\mathrm{nPVI}$ category from the Romantic composers period reveals that again, there is essentially no trend during this time period $\left(R^{2}=0.17, p=.13\right)$. Instead, what appears to be happening in this time period is that some time around 1840 to 1850 , a split occurs in compositional style, with one group of composers using high amounts of rhythmic variability more frequently than other composers. (The trendline in Figure 6 neatly divides these two groups visually from 1850 forward.) Table 3 below provides the composer, midpoint year, average overall nPVI, and the percentage of "high" nPVI for the composers in each group, using Schumann’s 1833 midpoint as a chronological starting point:

Table 3. Division of composers from 1850-1910 into high percentage vs. low percentage of "high" nPVI

\begin{tabular}{lccc}
\hline Composer & Midpoint year & $\begin{array}{c}\text { Average } \\
\text { overall nPVI }\end{array}$ & $\begin{array}{c}\text { Percentage of } \\
\text { "high” nPVI }\end{array}$ \\
\hline High Percentage/“Wagnerian” Group: & & \\
Wagner & 1848 & 63.9 & 78 \\
Suppé & 1857 & 52.7 & 61.8 \\
Bruckner & 1860 & 48.7 & 59.7 \\
J. Strauss & 1862 & 55.1 & 66.3 \\
Bruch & 1879 & 58.0 & 72.22 \\
R. Strauss & 1906.5 & 60 & 73.9 \\
& & & \\
Low Percentage/ "Brahmsian” Group: & & \\
Schumann & 1833 & 40.8 & 44 \\
Brahms & 1865 & 43.5 & 46.7 \\
Mahler & 1885.5 & 45.7 & 50 \\
Reger & 1894.5 & 41.3 & 44 \\
\hline
\end{tabular}

\section{AN ALTERNATE EXPLANATION}

This division of composers who frequently used high amounts of rhythmic variability, contrasted with those who did not, mirrors almost exactly the famous Wagner/Brahms rivalry sometimes known as the "War of the Romantics." This ideological and stylistic disagreement arose in the 1850s as composers aligned themselves with either the progressive New German School of Wagner and Liszt or with the more conservative camp surrounding Brahms (Walker, 1993).

With one exception, the composers in this data set with the overall higher nPVI averages, and higher percentages of "high" nPVI themes, are those mid- to late- $19^{\text {th }}$ century composers who aligned themselves with Wagner (note that Wagner himself, with his midpoint year of 1848, has the highest nPVI average and percentage of "high" nPVI themes). Those composers in the data set who aligned themselves with Brahms and his sensibilities have lower overall nPVI averages, and lower percentages of "high" nPVI themes. [4]

The results of a two-predictor multiple regression test, using midpoint year and Brahms/Wagner influence as the predictors, indicate that the midpoint year is not a significant predictor of percentage of "high" nPVI ( $p=.53)$, whereas the Brahms/Wagner alignment is a significant predictor $(p=.03)$. This indicates that their allegiance in the "War of the Romantics" is a far better predictor of whether that composer will have an overall high percentage of "high" nPVI themes (Wagnerians) or an overall low percentage (Brahmsians).

In addition, a one-way ANOVA between the pre-1825 (Daniele's "Baroque/Classical") composers (including Beethoven, Weber, and Schubert, who were too early to choose sides in the "War"; mean "high" nPVI percentage $=40.99$ ), the post-1825 "Wagnerian" composers (see Table 3, mean "high" nPVI percentage $=68.64$ ), and the post-1825 "Brahmsian" composers (see Table 3, including Mendelssohn, mean "high" nPVI percentage $=46.712$ ) reveals no significant difference between the percentage of "high" nPVI in pre-1825 "Baroque/Classical" composers and the post-1825 "Brahmsian" composers ( $p=.24)$, but indicates a significant difference between the post-1825 "Wagnerian" composers and the other two categories ( $p<.001$ for both). 


\section{DISCUSSION}

Rather than a general trend over time, or the waning influence of Italian music, it appears as though the rising trend line identified by Daniele in his Figure 1 is statistically primarily the result of composers who aligned themselves with Wagner in the "War of the Romantics" or with Wagnerian/Lisztian sensibilities in general. [5] Stylistically, they tended to compose with higher amounts of rhythmic variability, and did so more frequently, and this influences the overall trend line. Comparing the data from this group of composers to the earlier generation of composers, and to their contemporary composers not sympathetic with Wagner and Liszt, reveals that there is no significant trend over time for rhythmic variability in German music to rise except in the late 1800s.

Because much of the data is the same, this explanation also explains the finding of the general trend over time for Austrian and German composers in Daniele and Patel (2013; their Figure 2, reproduced in Figure 7 below, with German composers in solid dots and Austrian in white). Their Figure 2 illustrates the same stylistic separation from 1850 forward, although it is harder to see because of the scale of the yaxis. Although there are some composers in the 2013 study who are not represented in the current study, the data points above the trend line from 1850 onwards are, as here, Wagner, von Suppé, Johann Strauss Jr., Bruch, and Richard Strauss, and these data points are the ones pulling the overall trend significantly upwards.

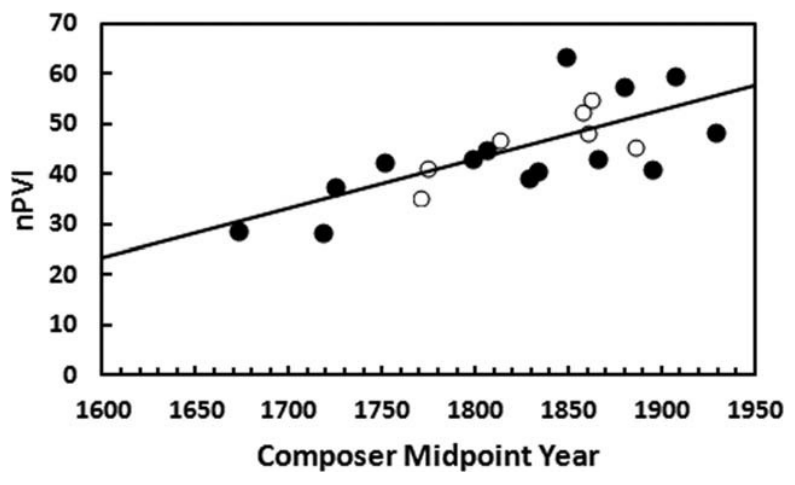

Figure 7. Figure 2, reproduced from Daniele and Patel (2013).

\section{CONCLUSIONS AND FUTURE DIRECTIONS}

Thus it does not appear as though the late 1700s were a time when composers were making a "conscious choice to write 'German' themes,"(p. 231) nor is there an overall trend in German compositional style towards the use of more rhythmic variability. With a larger data set, it becomes clearer that the "conscious choice" Daniele was seeking in the late 1700s may have happened post-1850 instead, manifested not by the waning influence of Italian music but rather by Wagner and his acolytes.

In his conclusion, Daniele conjectures that the large proportion of "high nPVI" themes for Wagner and Richard Strauss in his smaller data set are "suggestive evidence for incipient $20^{\text {th }}$ century rhythms."(p. 231)[6] As Daniele suggests, it would indeed be an interesting future study to investigate other late $19^{\text {th }}$ and early $20^{\text {th }}$ century composers and trends to see if the tendency to use high amounts of rhythmic variability continued, and if it was confined to specific groups of composers or compositional styles. This alternate interpretation of Daniele's data set shows the importance of a historically informed approach to using corpus studies and empirical musicology to study quantitative aspects of stylistic trends.

Another possible line of inquiry would involve the relationship between nPVI and meter. In my own work (VanHandel and Song (2010), not cited in Daniele (2016)), I have found an important relationship between $\mathrm{nPVI}$ and the use of compound vs. simple meters; composers who use compound meter more frequently tend to have higher overall average nPVI values. A potential line of inquiry may be whether there was a measurable change in either compositional use of compound meter in the late $19^{\text {th }}$ 
century, or whether there was a change in how composers were treating rhythm in compound and simple meters overall.

\section{Acknowledgements}

The author would like to thank Daniel Alt and Nathan Burroughs for programming and statistical assistance.

\section{NOTES}

[1] Correspondence can be addressed to: Dr. Leigh VanHandel, Michigan State University, College of Music, 333 West Circle Drive, Michigan State University, East Lansing MI 48823, email: lvh@msu.edu.

[2] There are also composers represented in the Barlow and Morgenstern Dictionary of Musical Themes who were not included in either study; for example, Buxtehude, who may have been excluded for language issues, and Pachelbel, who was most likely excluded for a small number of themes (5). Daniele and Patel (2013) discuss the language rationale for not including other composers, including Handel and J.C. Bach, but do not specifically discuss Buxtehude.

[3] Hindemith is also included in the Daniele and Patel (2013) data set, but has been excluded here because he is not a Romantic composer.

[4] Max Bruch appears in the "high" category here, despite being an outspoken critic of Wagner; however, he was highly influenced by folk song, including Scottish folk song, which is known to have a high amount of rhythmic variability (McGowan \& Levitt, 2011; Temperley \& Temperley, 2011). That folk song influence may have affected Bruch's use of rhythmic variability in his compositions.

[5] Liszt's Hungarian birth and frequent moves around Europe prevent his official inclusion in the present data set; however, testing the inclusion of his data from the Dictionary results in him falling into the lower end of the "high" category (midpoint year $=1848.5$, average $n P V I=48.1$, percentage of high nPVI = 57.5), and does not change the outcome of any of the significance tests.

[6] Daniele also suggests that the results in the 2016 study do not change if you raise the cutoff for the number of themes to 100 and remove the data for Wagner and Johann Strauss, Jr.; this is likely because the data point for Richard Strauss would remain and would continue to exert a disproportionate influence on the linear regression.

\section{REFERENCES}

Barlow, H. \& Morgenstern, S. (1983). A dictionary of musical themes. London, UK: Faber and Faber.

Daniele, J. (2016). A tool for the quantitative anthropology of music: Use of the nPVI equation to analyze rhythmic variability within long-term historical patterns in music. Empirical Musicology Review, 11(2), 228-232. https://doi.org/10.18061/emr.v11i2.4893

Daniele, J. \& Patel, A. (2013). An empirical study of historical patterns in musical rhythm: Analysis of German \& Italian classical music using the nPVI equation. Music Perception, 31(1), 10-18. https://doi.org/10.1525/mp.2013.31.1.10

Daniele, J. \& Patel, A. (2015). Stability and change in rhythmic patterning across a composer's lifetime: A study of four famous composers using the nPVI equation. Music Perception, 33(2), 255-265. https://doi.org/10.1525/mp.2015.33.2.255

Grove Music Online. Oxford Music Online. (Multiple articles accessed March 20-24, 2016). 
London, J. (2013). Building a representative corpus of classical music. Music Perception, 31(1), 68-90. https://doi.org/10.1525/mp.2013.31.1.68

McGowan, R., \& Levitt, A. (2011). A comparison of rhythm in English dialects and music. Music Perception, 28(3), 301-311. https://doi.org/10.1525/mp.2011.28.3.307

Temperley, N, \& Temperley, D. (2011). Music-language correlations and the 'Scotch Snap.” Music Perception, 29(1), 51-63. https://doi.org/10.1525/mp.2011.29.1.51

VanHandel, L. (2006). Trends in/over time: Rhythm in speech and music in $19^{\text {th }}$ century art song. Proceedings of the $9^{\text {th }}$ International Conference on Music Perception and Cognition. Bologna, Italy: Bononia University Press.

VanHandel, L., \& Song, T. (2010). The role of meter in compositional style in 19th century French and German art song. Journal of New Music Research, 39(1), 1-11.

https://doi.org/10.1080/09298211003642498

Walker, A. (1993). Franz Liszt: The Weimar Years. Ithaca, NY: Cornell University Press. 